\title{
TRICHOBEZOAR (HAIRBALL) CAUSING ACUTE INTESTINAL OBSTRUCTION IN A CHILD AGED THREE YEARS
}

\author{
BY
}

\author{
RONALD C. MACKEITH, B.M., D.C.H., \\ Resident Pædiatrician \\ AND
}

A. H. SANGSTER, M.D., F.R.C.S.,

Assistant Medical Officer, St. James's Hospital, London County Council

Although not uncommon in mental hospital patients, a trichobezoar in a child is not often seen. Besides being rare, the condition is of considerable historical interest. The word 'bezoar,' derived from Arabic 'badzehr' or from Persian ' pad zahr,' signifying counter-poison or antidote, is the term applied to masses found in the intestine and stomach of both men and animals. Bezoars have been known since the twelfth century B.C. They were supposed to have marvellous medicinal and mystical properties ; and this was the belief as late as the eighteenth century A.D., Tinct. Bezoardio being included in the materia medica. Such was the considered value of bezoar that many counterfeits were made. To offset this trade, elaborate tests, as futile as the bezoar, were formulated to differentiate true from false (Eusterman and Balfour, 1937).

Bezoars which are found in human beings are classified as : trichobezoar (hairball) ; trichophytobezoar (ball of hair and vegetable fibre) ; phytobezoar (ball of vegetable fibre); and concretion. The first real case was described by Baudement in 1779 ; and the first reported removal by operation was in 1883 (Schwartzman, 1937).

These foreign bodies may produce no symptoms, but those most commonly found are epigastric pain, nausea, vomiting and diarrhœa. A palpable tumour may be present, and the most important aid in diagnosis, according to Eusterman and Balfour (1937), is the radiological examination. By using barium, a non-opaque foreign-body in the stomach is outlined. When found in children, trichobezoar is usually in the stomach.

\section{Case report}

R. C., a male child aged $3 \frac{1}{2}$ years was in the hospital on account of a dry skin eruption attributed to the use of an alkaline soap. He had been in the 
hospital six months before for the same trouble. He was a fair-haired child in rather poor general condition. He was not obviously mentally defective, nor did he pull his hair out. On March 12,1939, he vomited once, but on examination he showed no signs of illness. The next day he vomited repeatedly, and was fretful and ill. A lumbar puncture, done by the house-physician on a suspicion of meningitis, yielded a clear fluid. When seen later that evening by one of us (R. C. M.) he was found to be restless and ill, with marked dehydration : but afebrile and not suffering from shock. His facial colour was good. He appeared to have abdominal pain and resented examination of the abdomen, but nothing abnormal was found there. Rectal examination was negative. The bowels had not been open for thirty-six hours. There was no evidence of intussusception. A diagnosis of acute high intestinal obstruction was made, but after consultation with a surgeon it was decided not to operate. In view of the child's dehydration, a ureteric catheter was tied into the saphenous vein at the ankle and a continuous intravenous drip infusion started, using Hartman's solution followed by 10 per cent. glucose solution. The child improved greatly in general condition and for twenty hours there was no further vomiting. After this interval, the vomiting started again and the question of a laparotomy was reconsidered, and the child was referred (on March 14) to one of us (A. S.) for a second surgical opinion. The child was obviously ill and still somewhat dehydrated. In the abdomen a mass was felt on the right side close to the umbilicus. This was elongated and sausage-shaped.

As the child was moved from the dorsal to the lateral position, the tumour swung on its transverse axis from a vertical to a transverse lie. An exact diagnosis as to the nature of the mass was not made, but a laparotomy was done for the acute obstruction.

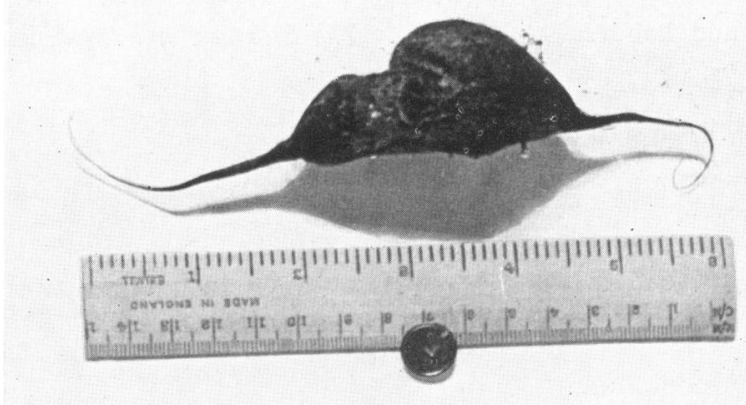

FIG. 1. 
At the operation, a mass was found blocking the jejunum about eighteen inches from the duodenal-jejunal flexure, the bowel above being grossly distended. The mass was removed from the jejunum, the latter was repaired and the abdomen closed. The intravenous drip was continued for some time after the operation.

The child managed to make a complete examination of his incision, with resultant sepsis, but apart from this his convalescence was uneventful and he was discharged a month after the operation, completely healed and in good health.

The illustration (fig. 1) shows the trichobezoar as it appeared on removal from the jejunum. The 'body' measures $2 \frac{1}{2} \times 1 \frac{1}{2} \times 1 \frac{1}{4}$ inches, and has a ' tail' about 2 inches long at each end. It is surprising that it could pass through the pylorus of a child of this age.

The colour of the hair is black, which raises the question of its origin, unless fair hair becomes black under prolonged action of the digestive juices.

\section{Discussion}

The case is of interest partly for some unusual clinical features. The surgeon who first saw the case was unwilling to operate partly because he felt that no adequate cause for obstruction was apparent; and the temporary remission of symptoms appeared to confirm that he was right. It would seem worth while considering bezoar in obscure abdominal cases in children, as well as in adults. This case is reported because of the apparent rarity of a trichobezoar in a male child, and the even more unusual feature of its causing acute intestinal obstruction by lodging in the jejunum.

Thanks are due to Sir Frederick Menzies, Chief Medical Officer of the L.C.C., and to Dr. W. L. MacCormac, Medical Superintendent of St. James's Hospital, L.C.C., for permission to publish this case.

\section{REFERENCES}

Eusterman, G. B., and Balfour, D. C. (1935). The Stomach and Duodenum, Philadelphia and London.

Schwartzman, J. (1937). J. Pediat., 11, 691. 